\title{
PRESSURE DROP AND FLOW UNIFORMITY ANALYSIS OF COMPLETE EXHAUST SYSTEMS FOR DIESEL ENGINES
}

\author{
André Bergel ${ }^{1}$ \\ Edson L. Duque ${ }^{2}$ \\ General Motors - Global Propulsion Systems - South America ${ }^{12}$ \\ E-mail: andrebergel84@yahoo.com.br ${ }^{1}$ \\ E-mail: edson.duque@gm.com ${ }^{2}$
}

\section{SUMMARY}

This analysis takes into account the complete exhaust system (turbo, DOC, DPF, SCR, Muffler, mixers and pipes) to evaluate pressure drop and flow uniformity. This procedure can guide us in order to: identify the most restricting flow element, improving geometry layout of these elements, improving the uniformity of the flow, to reduce velocity at minimum possible value inside each element, improving residence time and conversion efficiencies ${ }^{[1]}$. It was used real conditions of load for engine exhaust gas flow, temperature, turbine rotation, etc.

\section{INTRODUCTION}

Nowadays, a complete diesel after treatment system consists of various components: diesel oxidation catalyst (DOC), selective catalytic reduction (SCR), diesel particulate filter (DPF), and others. In order to meet stringent emission norms, various combinations of these components can be employed. Additionally, each component performance depends also the other components.

Computational fluid dynamics (CFD) plays an important role in performance evaluation of all exhaust system components, reducing costs of physical tests and providing reliable results in order to make the best choice in terms of performance, quality and cost.

\section{METHODOLOGY}

\subsection{Exhaust Lines Layout and Load Cases}

In this analysis were used two different exhaust line geometries: first is for medium size engines (ME) and second is for large size engines (LE) for passenger cars.

The ME layout (Figure 01) is composed by DOC, DPF and two SCR's, while LE layout (Figure 02) is composed by DOC, two SCR's, DOC and DPF. Also, in the geometries are included mixers, used to promote a better mixture and improve evaporation of injected urea and fuel, sensor's external shell, urea injector house, etc. 
In Table 01 and 02 can be seen a normalized summary of load cases used in the analysis. The load cases are averaged values measured in the exhaust system when the complete car is submitted to some emissions validation procedure, like FTP75 or US06 ${ }^{[2]}$ federal standard procedures, representing a percent of the full load condition. The normalization procedure is necessary in order to do not disclose sensible data from GM engines and suppliers. It was normalized separately for each analyzed engine, and for each property or result evaluated.

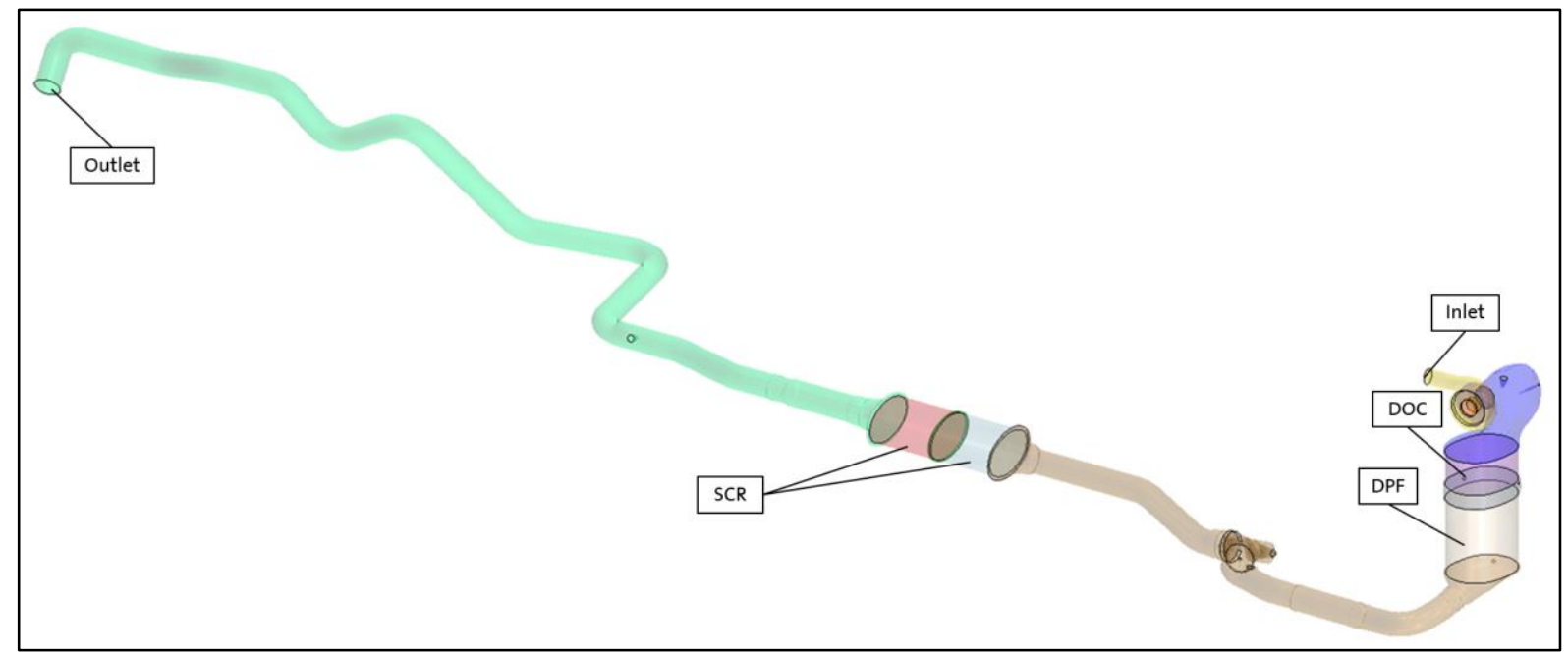

Figure 01 - ME exhaust system layout.

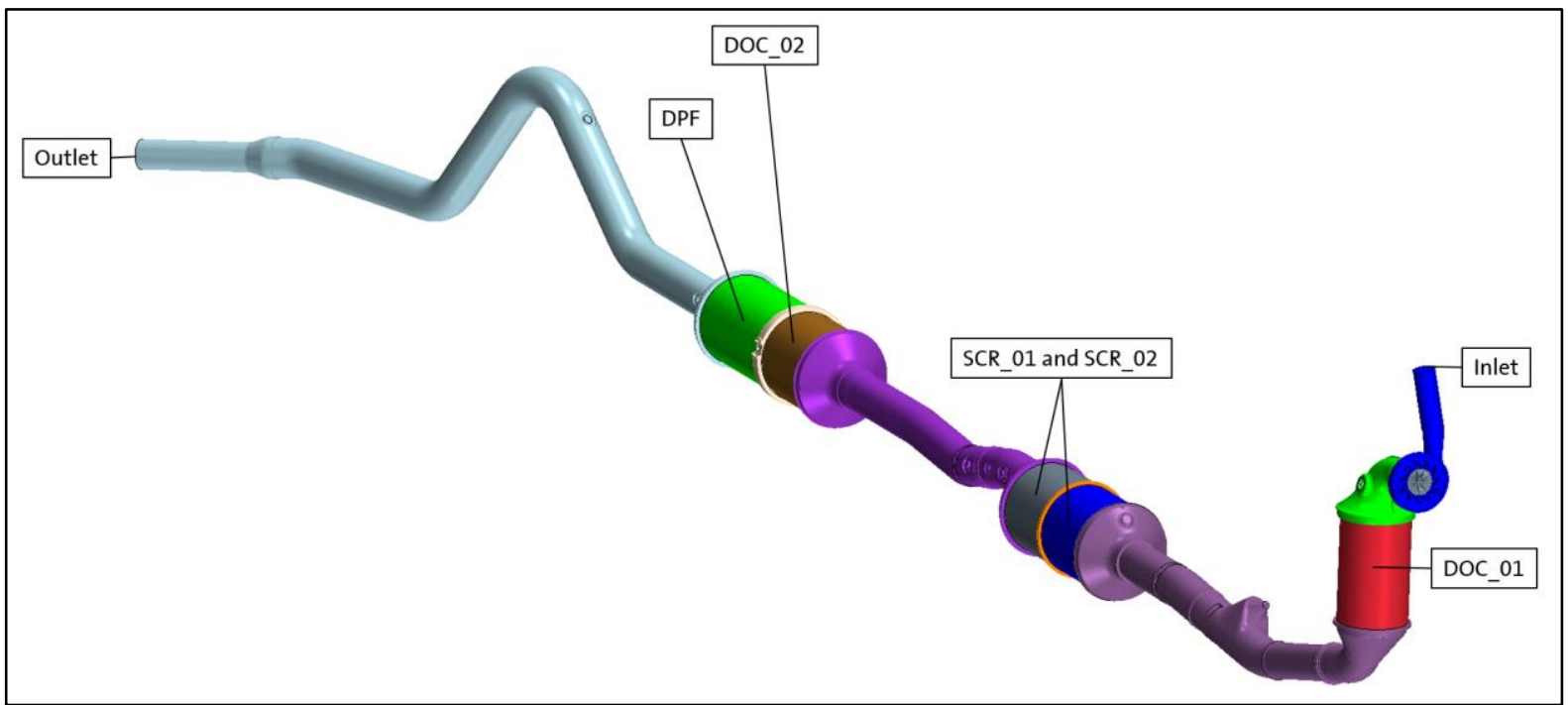

Figure 02 - LE exhaust system layout. 
Table 01 - Normalized load cases used in ME analysis.

\begin{tabular}{|c|c|c|c|c|c|}
\hline \multicolumn{2}{|c|}{ ME - Normalized Values } & Case 01 & Case 02 & Case 03 & Case 04 \\
\hline Mass flow rate & $\mathrm{kg} / \mathrm{h}$ & 0.1000 & 0.2500 & 0.5000 & 1.0000 \\
\hline Turbo Inlet Total temperature & $\mathrm{K}$ & 0.4621 & 0.5881 & 0.7031 & 1.0000 \\
\hline Turbo Outlet Total temperature & $\mathrm{K}$ & 0.4482 & 0.5429 & 0.6376 & 0.8716 \\
\hline Turbo rotational speed & $\mathrm{RPM}$ & 0.1826 & 0.5710 & 0.7080 & 1.0000 \\
\hline Turbo VGT position & ${ }^{\circ}(\mathrm{Deg})$ & 0.3733 & 0.4188 & 0.8006 & 1.0000 \\
\hline Outlet Static pressure & $\mathrm{kPa}$ & \multicolumn{5}{c|}{$101,325.0$} \\
\hline
\end{tabular}

Table 02 - Normalized load cases used in LE analysis.

\begin{tabular}{|c|c|c|c|c|c|}
\hline LE - Normalized Values & Case 01 & Case 02 & Case 03 & Case 04 \\
\hline Mass flow rate & $\mathrm{kg} / \mathrm{h}$ & 0.0973 & 0.2500 & 0.5000 & 1.0000 \\
\hline Turbo Inlet Total temperature & $\mathrm{K}$ & 0.4780 & 0.5937 & 0.7207 & 1.0000 \\
\hline Turbo Outlet Total temperature & $\mathrm{K}$ & 0.4701 & 0.5695 & 0.6688 & 0.9198 \\
\hline Turbo rotational speed & $\mathrm{RPM}$ & 0.2452 & 0.4679 & 0.7424 & 1.0000 \\
\hline Turbo VGT position & ${ }^{\circ}(\mathrm{Deg})$ & 0.2157 & 0.4610 & 0.6415 & 1.0000 \\
\hline Outlet Static pressure & $\mathrm{kPa}$ & \multicolumn{5}{|c|}{$101,325.0$} \\
\hline
\end{tabular}

\subsection{Boundary Conditions}

In this approach, inlet condition is modeled as constant mass flow at a fixed temperature, using air as work fluid. Also, outlet condition is the atmosphere status condition, $300[\mathrm{~K}]$ and 101.325 or $103.825[\mathrm{kPa}]$.

Walls are modeled using a free convection approach of heat exchange between environment and exhaust gas, providing a suitable heat transfer coefficient and ambient temperature.

The after treatment components are modeled as a porous media, providing lengthwise coefficients of pressure drop for each component. Porous media coefficients used in the analysis are normalized and provided in the Table 03, where $\alpha$ and $\beta$ are variables of software to simulate porous media.

Table 03 - Normalized values of porous media cefficients used in analysis.

\begin{tabular}{|c|c|c|c|c|}
\hline \multirow{2}{*}{ Component } & \multicolumn{2}{|c|}{ ME } & \multicolumn{2}{c|}{ LE } \\
\cline { 2 - 5 } & Normalized $\alpha$ & Normalized $\beta$ & Normalized $\alpha$ & Normalized $\beta$ \\
\hline DOC 01 & 0.6119 & 0.2713 & 0.2906 & 0.2614 \\
\hline DOC 02 & --- & --- & 0.1864 & 0.1286 \\
\hline DPF & 1.0000 & 1.0000 & 0.7576 & 0.4586 \\
\hline SCR 01 & 0.1259 & 0.2712 & 0.3430 & 0.1592 \\
\hline SCR 02 & 0.1259 & 0.2712 & 0.3430 & 0.1592 \\
\hline
\end{tabular}


Once temperature boundary conditions are measured at turbine outlet, it is necessary to correct temperature at turbine inlet in order to match this value.

Turbine geometry was included in the model in order to take into account the flow swirl due to turbine wheel rotation, modeled using Moving Reference Frame (MRF) approach.

\subsection{Physics Modeling}

Exhaust gas was modeled as air with ideal gas approach, using $k-w$ turbulence model and Darcy's law to porous media, and some properties was changed to mimic the exhaust gas behavior, like molar weight, etc.

It was used a commercial numerical code to solve the mass, momentum and energy conservation equations, turbulence models and all physics modeling in these analysis. STAR$\mathrm{CCM}+$ is a well-recognized solution to tackle problems involving complex geometries and multi-physics problems ${ }^{[3]}$.

\subsection{Meshing Setup and Details}

It was used a polyhedral mesh, using prismatic elements near the walls, extruding the inlet and outlet faces to correctly apply the boundary conditions ${ }^{[4]}$. There are about 2.5 million elements in each model, including all extrusions, prismatic and polyhedral elements

There are some refinements zones in the model, like sensors, variable angle blades and in some faces close each one. There was required to improve quality mesh metrics, reduce convergence time and improve results quality.

\section{RESULTS}

The pressure drop analysis can guide to find more restrictive element in the exhaust system, indicating where it must concentrate efforts to reduce system pressure drop. It is evaluated at full load conditions $\left(4^{\text {th }}\right.$ cases $)$.

Flow uniformity can drive designers in order to improve flow distribution at inlet of each porous media component (DOC, DPF and SCR), once this flow distribution plays an important role in the exhaust gas residence time and conversion efficiency. Flow uniformity is evaluated at intermediary load conditions $\left(1^{\text {st }}, 2^{\text {nd }}\right.$ and $3^{\text {rd }}$ cases $)$.

\subsection{Pressure Drop}

In this analysis, all normalized values are related to program value target that can be seen in the Figure 03 and 04, below. 


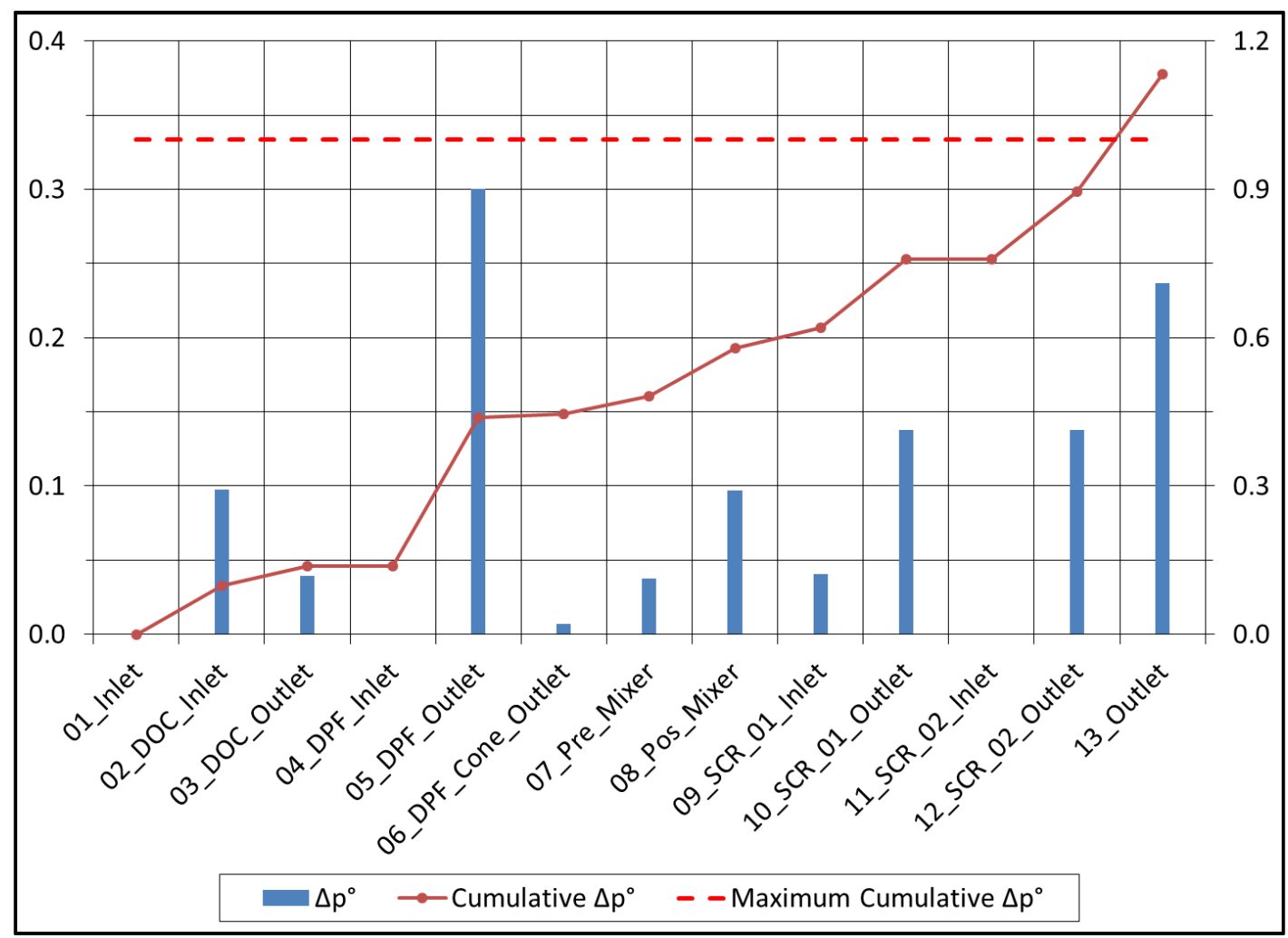

Figure 03 - Normalized pressure drop ME.

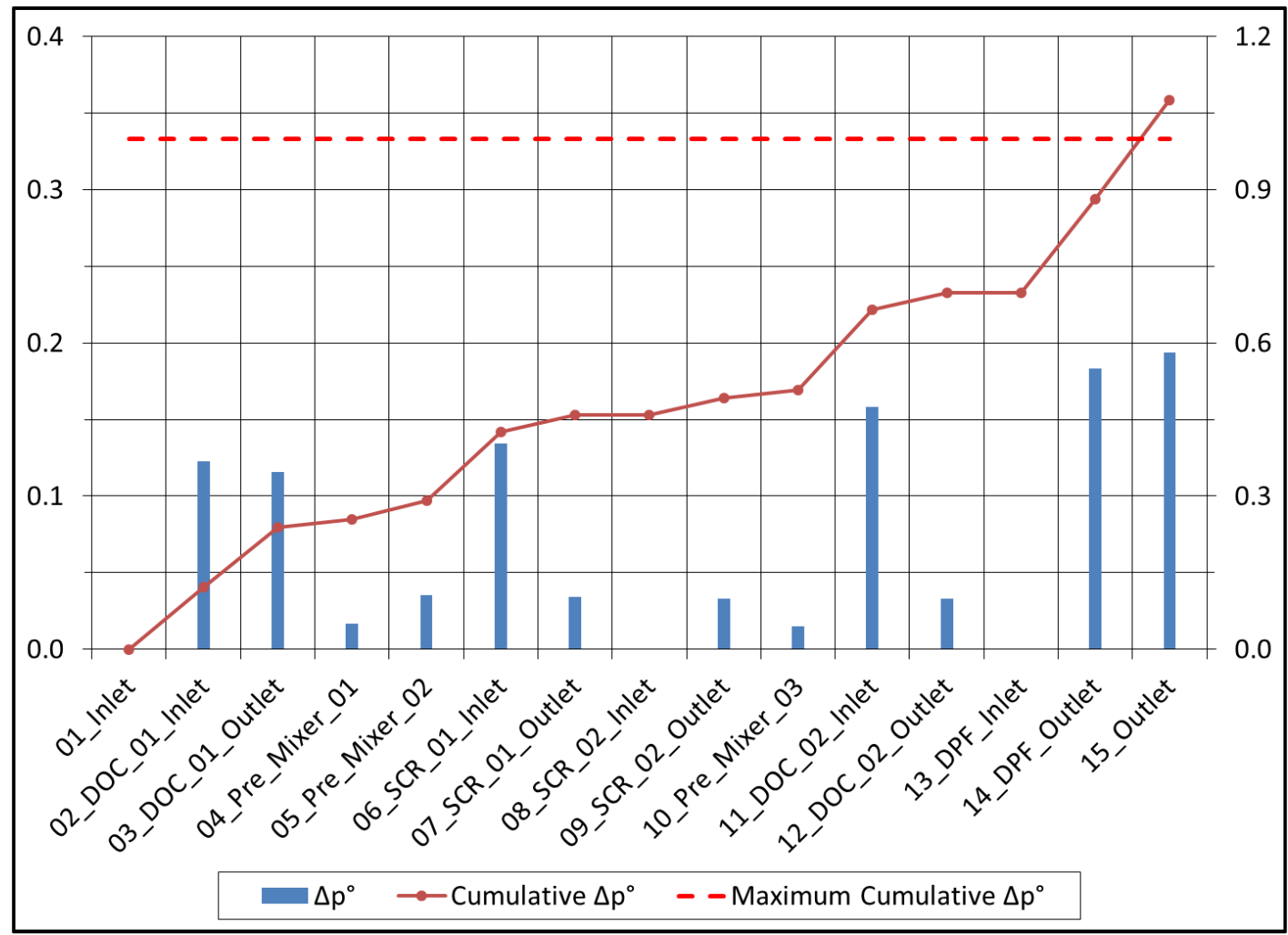

Figure 04 - Normalized pressure drop LE. 
For both engines, the maximum cumulative value of pressure drop exceeds the target for complete exhaust system pressure drop. For ME can notice that most restricting components are: Inlet/DOC Inlet (Pipe 01), DPF, Mixer 01, SCR 01 and SCR 02. For LE, the most restrictive elements are: Inlet/DOC Inlet (Pipe 01), DOC 01, Mixer 02, Mixer 03 and DPF. The outlet pressure drop is high due to the exiting exhaust gas velocity. Also, all mixers have different geometries, explaining the difference between pressure drop values, excepting mixer 02 and 03 of LE, that are same.

\subsection{DOC Flow Uniformity and Velocity Distribution}

The flow uniformity and normalized average velocity for all DOC's are presented in the Table 04 and Figures 05 to 07.

Table 04 - Flow uniformity and normalized velocities.

\begin{tabular}{|c|c|c|c|c|c|c|}
\hline \multirow{2}{*}{ Component } & \multicolumn{3}{|c|}{ Flow Uniformity } & \multicolumn{3}{c|}{ Normalized Mean Velocity } \\
\cline { 2 - 7 } & Case 01 & Case 02 & Case 03 & Case 01 & Case 02 & Case 03 \\
\hline ME - DOC & 0.9918 & 0.9833 & 0.9708 & 0.0723 & 0.2103 & 0.4509 \\
\hline LE - DOC 01 & 0.9876 & 0.9631 & 0.9283 & 0.1651 & 0.4859 & 1.0000 \\
\hline LE - DOC 02 & 0.9928 & 0.9846 & 0.9697 & 0.0947 & 0.2951 & 0.6625 \\
\hline
\end{tabular}

From this table can be noticed that flow uniformity are high for all components, and the mean velocity are highest for DOC 01 of LE.
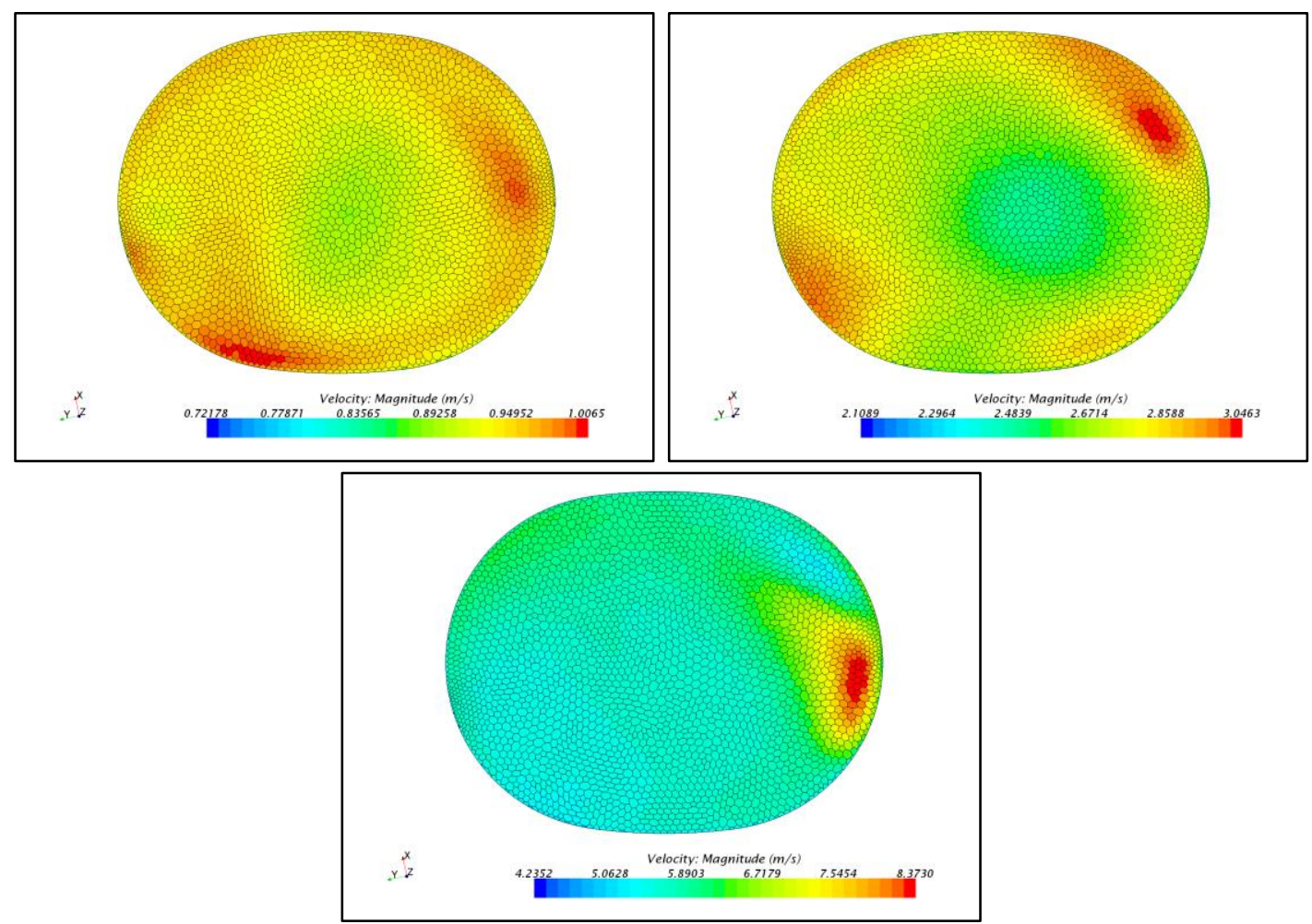

Figure 05 - ME DOC velocity distribution, for cases 01,02 and 03 , respectively. 

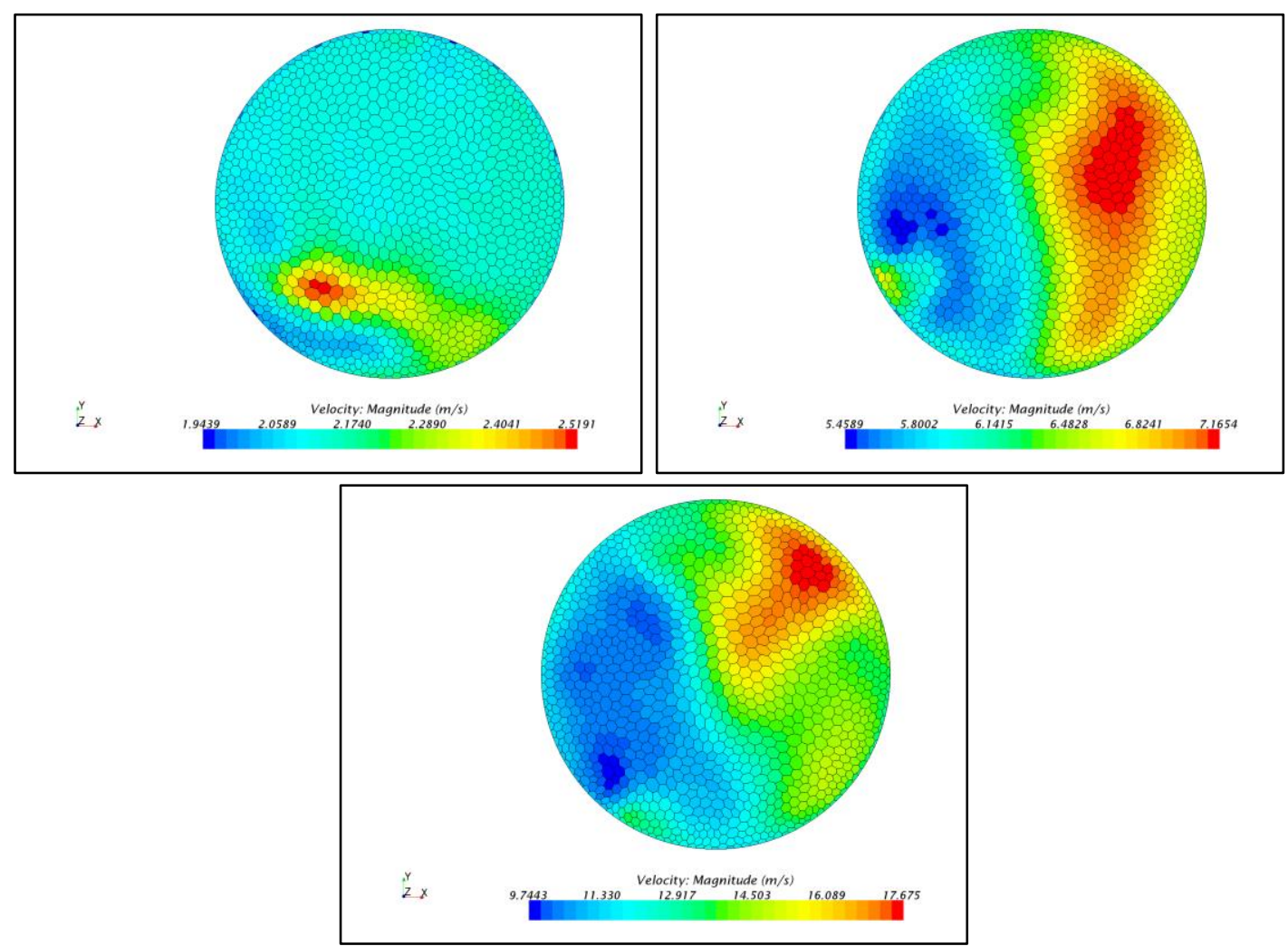

Figure 6 - LE DOC 01 velocity distribution, for cases 01,02 and 03, respectively.

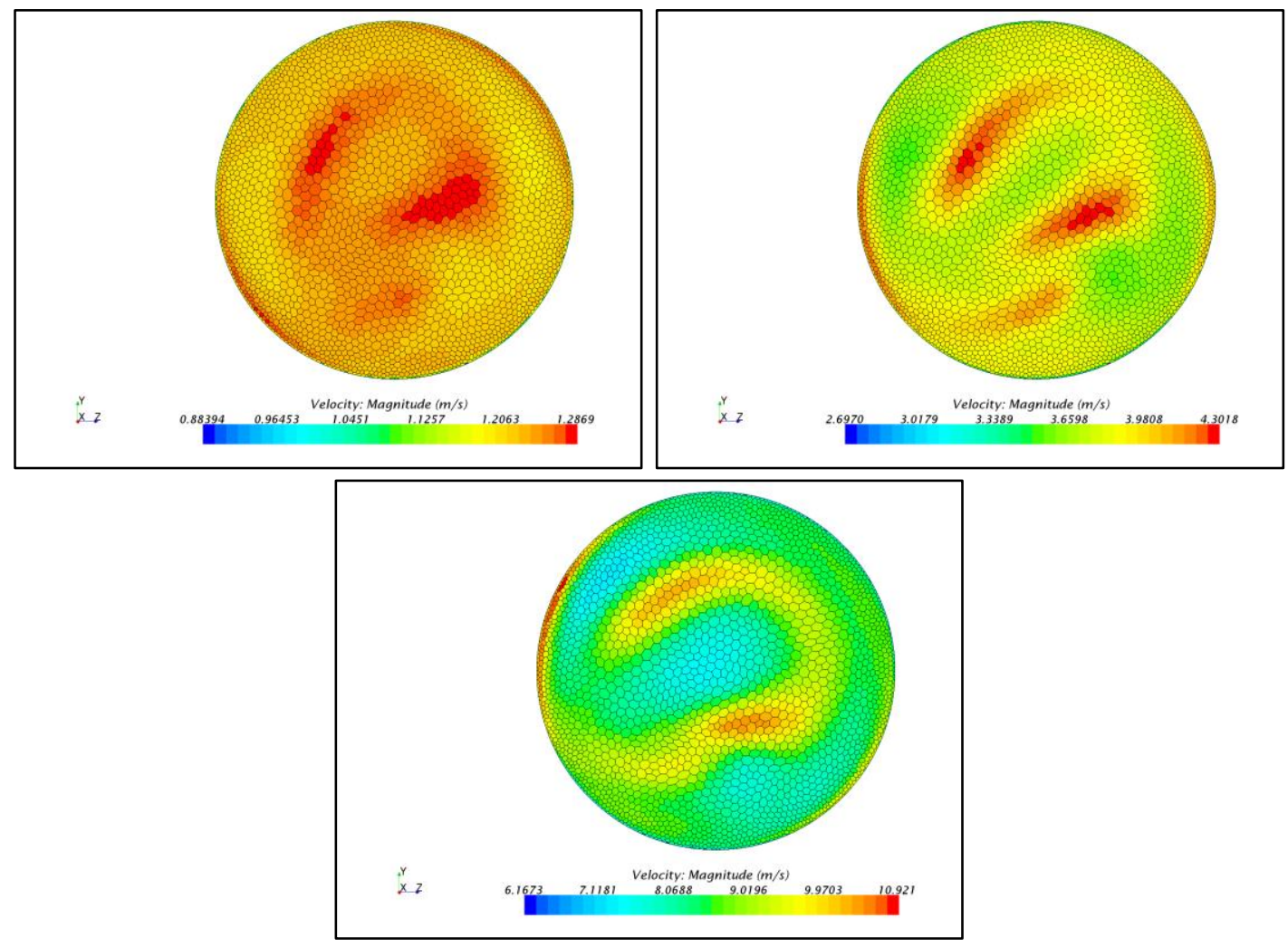

Figure 7 - LE DOC 02 velocity distribution, for cases 01,02 and 03, respectively. 
In these figures can be noticed higher velocity regions and differences between load cases in the flow at DOC inlet face.

\subsection{DPF Flow Uniformity and Velocity Distribution}

The flow uniformity and normalized average velocity for all DPF's are presented in the Table 05 and Figures 08 and 09.

Table 05 - Flow uniformity and normalized velocities.

\begin{tabular}{|c|c|c|c|c|c|c|}
\hline \multirow{2}{*}{ Component } & \multicolumn{3}{|c|}{ Flow Uniformity } & \multicolumn{3}{c|}{ Normalized Mean Velocity } \\
\cline { 2 - 7 } & Case 01 & Case 02 & Case 03 & Case 01 & Case 02 & Case 03 \\
\hline ME - DPF & 0.9986 & 0.9969 & 0.9943 & 0.1079 & 0.3150 & 0.6790 \\
\hline LE - DPF & 0.9991 & 0.9987 & 0.9979 & 0.1414 & 0.4424 & 1.0000 \\
\hline
\end{tabular}

From this table can be noticed that flow uniformity are high for all components, and the mean velocity are highest for DPF of the LE.

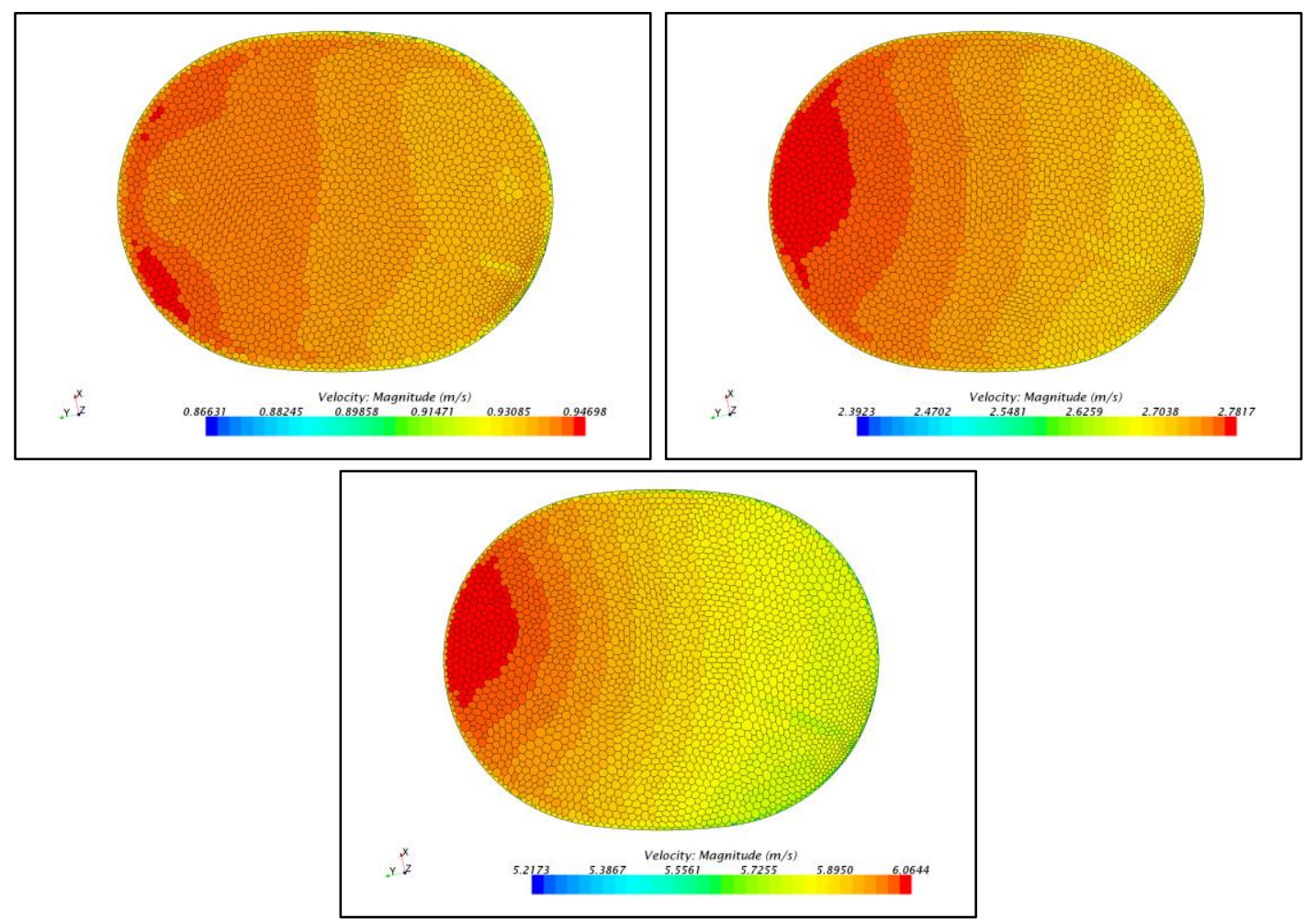

Figure 08 - ME DPF velocity distribution, for cases 01,02 and 03 , respectively. 

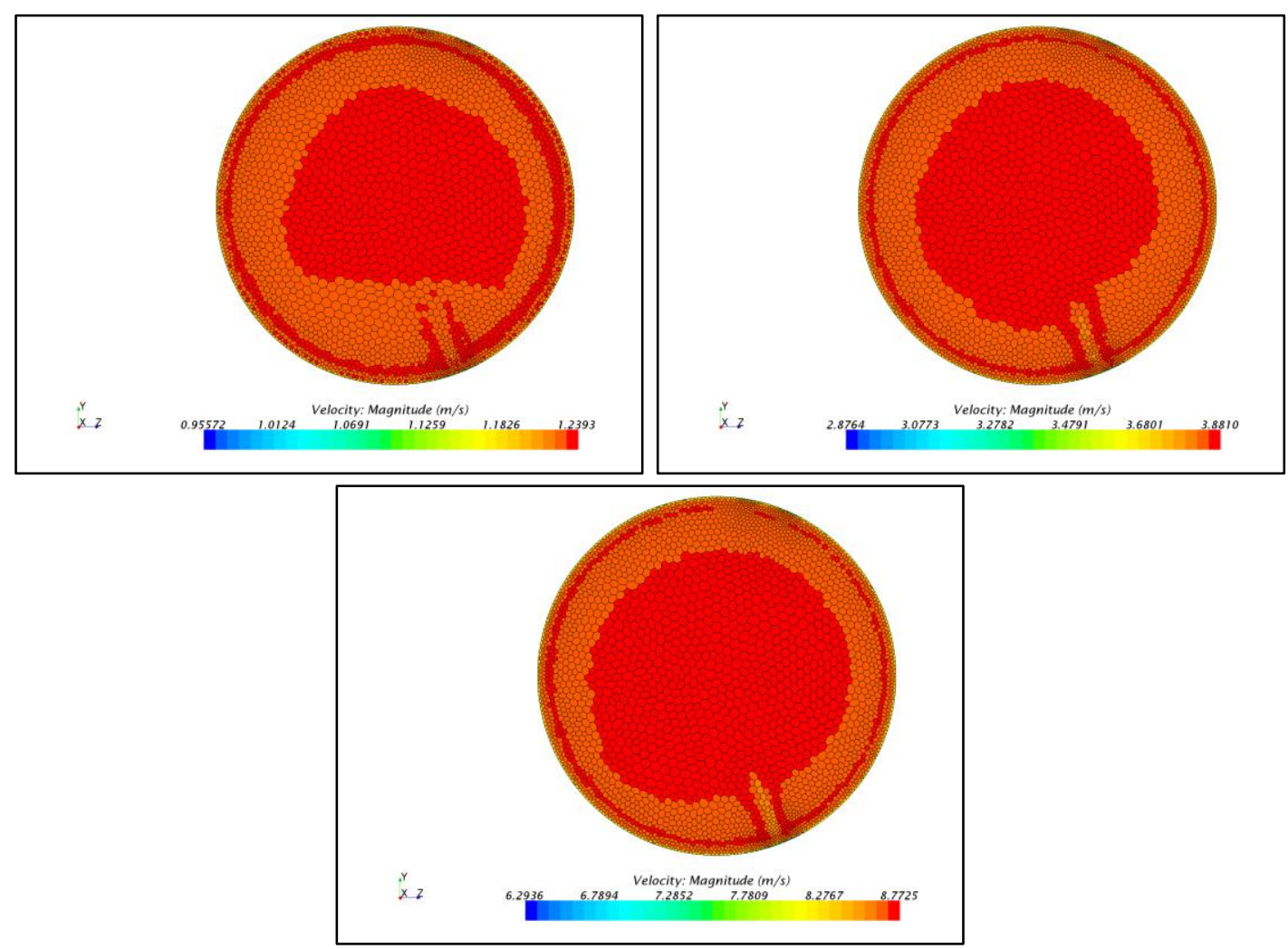

Figure 09 - ME DPF velocity distribution, for cases 01,02 and 03, respectively.

For DPF, the flow velocity distributions are more uniform than DOC outlets, once the upstream pipe stabilizes most of imbalances.

\subsection{SCR Flow Uniformity and Velocity Distribution}

The flow uniformity and normalized average velocity for all SCR's are presented in the Table 06 and Figures 10 to 12. The values for SCR 02 of ME are not available, once this wasn't a requisite from GM procedure when this analysis was performed.

Table 06 - Flow uniformity and normalized velocities.

\begin{tabular}{|c|c|c|c|c|c|c|}
\hline \multirow{2}{*}{ Component } & \multicolumn{3}{|c|}{ Flow Uniformity } & \multicolumn{3}{c|}{ Normalized Mean Velocity } \\
\cline { 2 - 7 } & Case 01 & Case 02 & Case 03 & Case 01 & Case 02 & Case 03 \\
\hline ME - SCR 01 & 0.9920 & 0.9798 & 0.9607 & 0.1430 & 0.4373 & 1.0000 \\
\hline LE - SCR 01 & 0.9966 & 0.9911 & 0.9767 & 0.1258 & 0.3826 & 0.8256 \\
\hline LE - SCR 02 & 0.9957 & 0.9919 & 0.9907 & 0.1260 & 0.3847 & 0.8347 \\
\hline
\end{tabular}

From this table can be noticed that flow uniformity are high for all components, and the mean velocity are highest for SCR 01 of the ME. 

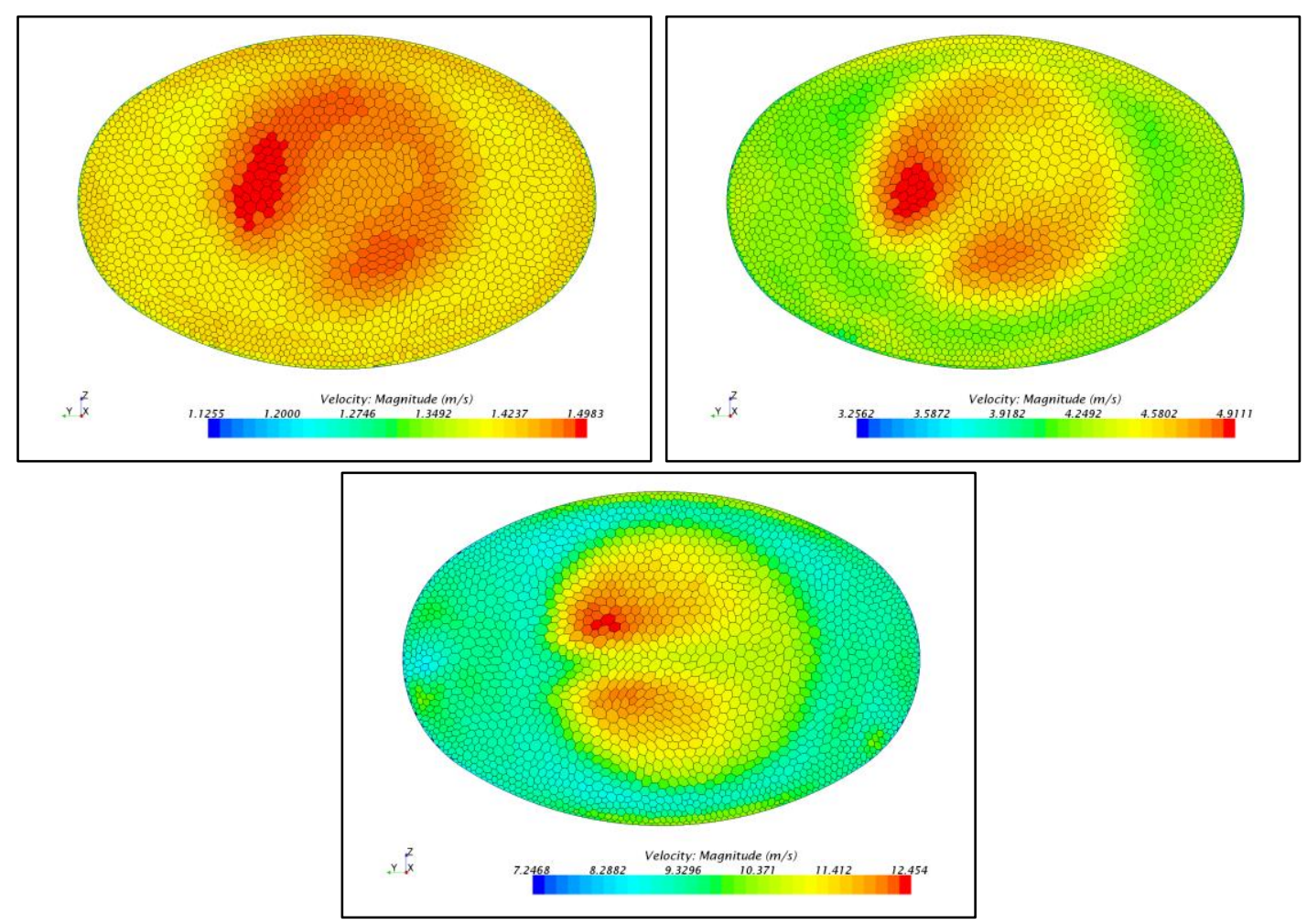

Figure 10 - ME SCR 01 velocity distribution, for cases 01,02 and 03 , respectively.

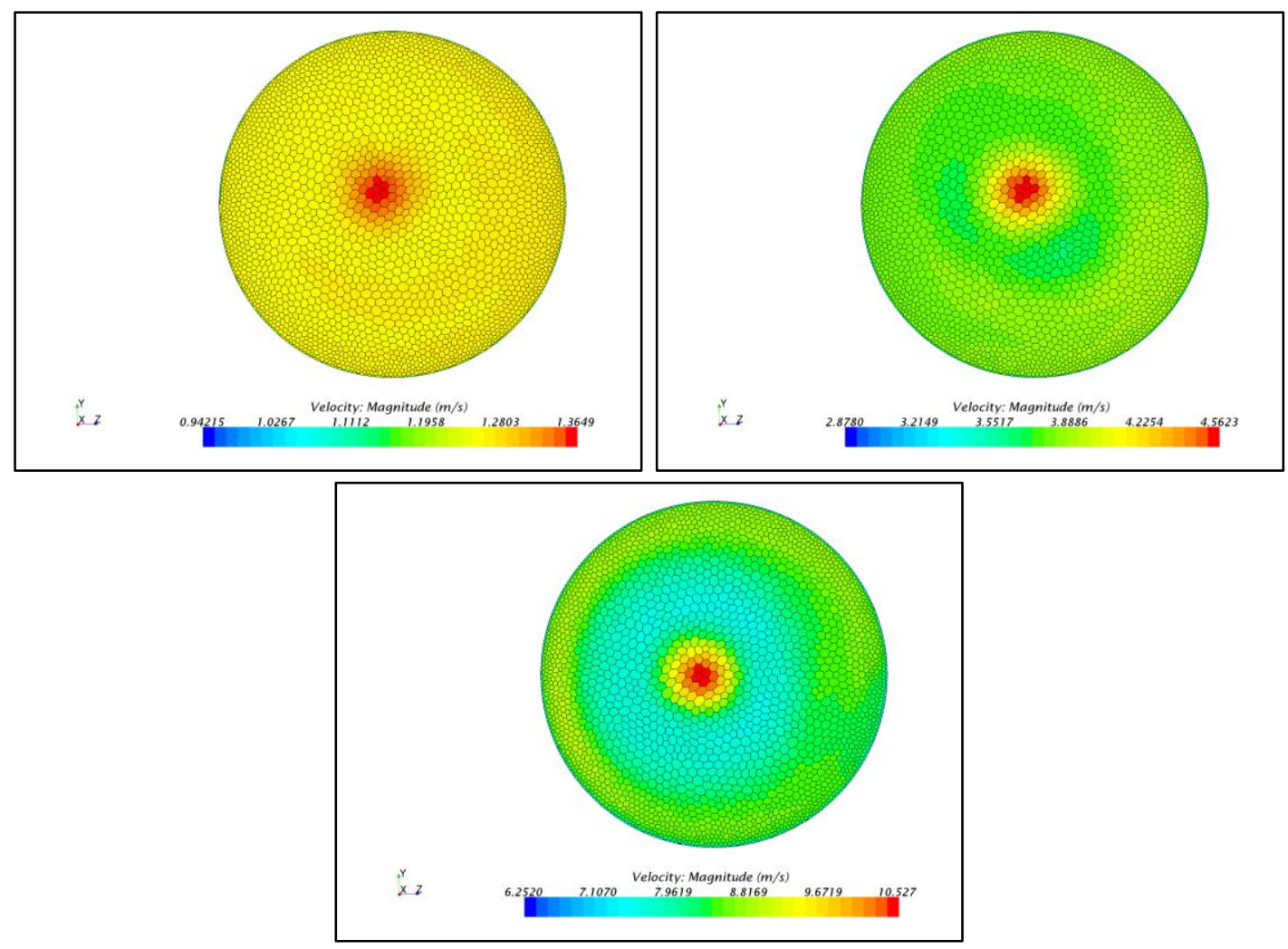

Figure 11 - LE SCR 01 velocity distribution, for cases 01,02 and 03, respectively. 


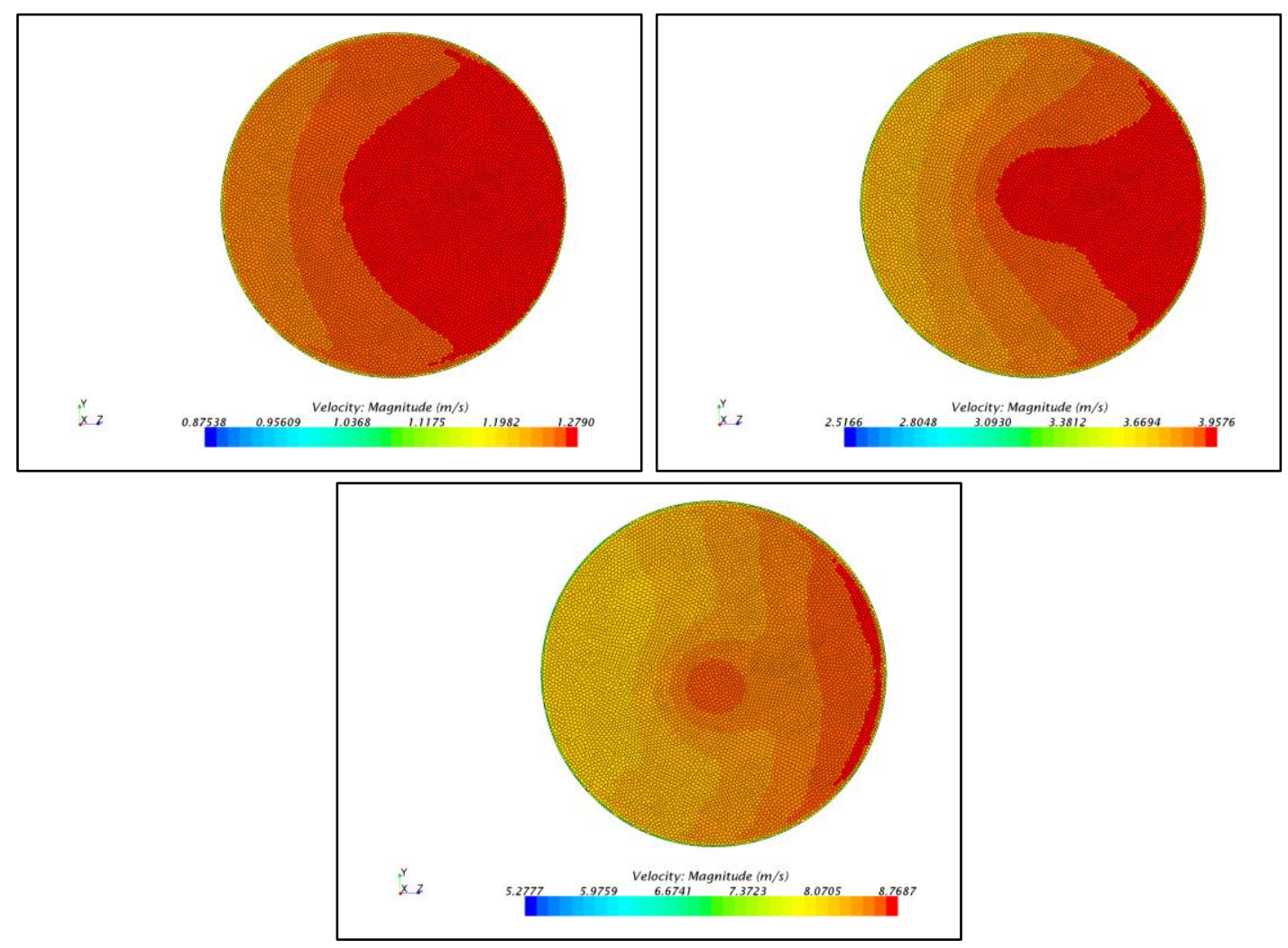

Figure 12 - LE SCR 02 velocity distribution, for cases 01, 02 and 03, respectively.

From these figures can be noticed that there is a well-defined pattern of flow distribution for first SCR for both geometries, and that can be explained by mixer geometry of each system. It can also be noticed that flow velocities in the second SCR of LE are less impacted by mixer geometry than the first SCR.

\section{CONCLUSIONS}

This methodology was proved efficient in order to predict more restrictive components of a complete exhaust system and help to understand influence of flow features in the uniformity and velocity distribution, like turbine rotation, mixers influence and sensors positioning.

Also, CFD analysis is able to reduce test costs, providing reliable results faster than physical methodology, with high quality and accuracy.

\section{ACKNOWLEDGMENTS}

To GM GPS South America and North America for providing physical and virtual space for the analysis.

To Chi-Jou Wang (GMNA) and Ivan Flaminio Cozza (GME) for the support with his great knowledge and experience. 


\section{REFERENCES}

[1] Heywood, John, Internal Combustion Engine Fundamentals, McGraw Hill, New York, NY, 1988.

[2] www.epa.gov, accessed on 27-May-2016.

[3] www.cd-adapco.com, accessed on 27-May-2016.

[4] Schlichting, H., Boundary Layer Theory, $7^{\text {th }}$ Edition, McGraw Hill, New York, NY, 1979. 